REVISTA VIRTUAL VIA INVENIENDI ET IUDICANDI

"CAMINO DEL HALLAZGO Y DEL JUICIO"

http://viei.usta.edu.co/ E-MAIL: revistainveniendi@usantotomas.edu.co

\title{
DERECHOS CIVILES DE LOS EXTRANJEROS EN ESPAÑA: GARANTÍAS RECOBRADAS POR LA JURISPRUDENCIA *
}

María Teresa Palacios Sanabria. Profesora de Carrera Académica de la Facultad de Jurisprudencia de la Universidad del Rosario, abogada de la Universidad del Rosario, especialista en derechos Humanos de la ESAP, Maestría en Derecho Constitucional de la Universidad de Sevilla, candidata a doctora por la Universidad de Sevilla.

Fecha de entrega: Septiembre 30 de 2009 Fecha de aprobación: Octubre 13 de 2009

\section{Resumen}

España es uno de los países que recibe constantemente flujos migratorios, y en tan solo unas décadas ha dejado de ser un país de emigrantes, para convertirse en un país de destino para los inmigrantes. ${ }^{1}$ Pese a que en el texto de su constitución consagra los derechos para los extranjeros, otorga a la potestad legislativa la posibilidad de configurar un gran grupo de derechos fundamentales, es así, como la Ley de extranjería que se ocupa de ello y en la mayor parte de los casos excede sus facultades y restringe fuertemente el ejercicio de los mismos. Es entonces la jurisprudencia la herramienta por medio de la cual éstos se reivindican y se hacen una realidad para los extranjeros.

Palabras claves: Extranjería, derechos de los extranjeros, inmigración.

\footnotetext{
Abstract

Spain is one of the countries that gets the most immigration flow, and for the last decades has passed from a country of emigrants to become the destination to

* El presente artículo es resultado de investigación y es una adecuación de la tesis defendida para optar por el título de Master Oficial en Derecho Constitucional en la Universidad de Sevilla.

${ }^{1}$ López Sala, A.M. (2005). Inmigrantes y Estados: la respuesta política ante la cuestión migratoria. Barcelona: Anthropos.
} 


\section{REVISTA VIRTUAL VIA INVENIENDI ET |UDICAND|}

"CAMINO DEL HALLAZGO Y DEL JUICIO"

http://viei.usta.edu.co/ E-MAIL: revistainveniendi@usantotomas.edu.co

immigrants [1]. Although Spain establish this last group's rights in its Constitution, gives the legal authority the possibility to set them up, accordingly, the immigration statute, develops and mostly, exceeds its faculties and restrains the use of their rights. It is the judge's say, the case law, the way to claim and restore them, turning them into a reality to Foreigners.

Key Words: Foreigners, Foreigners' Rights, Immigration Introducción

¿Son los extranjeros sujetos de derechos en el ordenamiento jurídico español? A primera vista la respuesta al problema puede ser positiva, sin embargo en el artículo que se presenta a continuación se hace un examen constitucional de los derechos que el texto superior asigna a este colectivo, y de la importancia que la jurisprudencia del Tribunal Constitucional Español ha cumplido en el reconocimiento de las garantías que se han visto limitadas por parte del legislador en ejercicio de su potestad de configuración legal. El método de estudio empleado ha sido el analítico, toda vez que se hace un examen de las disposiciones constitucionales que otorgan derechos a los extranjeros, y se confrontan con lo que se desarrolla legistivamente, para luego entrar a evaluar los pronunciamientos jurisprudenciales. El artículo es un resumen de la tesis de maestría efectuada en el marco del Master oficial de derecho constitucional realizado en la Universidad de Sevilla-España. La literatura revisada ha partido del análisis de la Constitución española como fuente original en la asignación de derechos a los extranjeros, se estudiaron así mismo las leyes de extranjería que han entrado a reglamentar este tema, y se tomaron como fuentes los principales pronunciamientos jurisprudenciales que han dado alcance a los derechos, sin perder de vista el aporte doctrinal español que ha permitido ilustrar la problemática en cuestión.

\section{Los derechos de los extranjeros en el texto constitucional de 1978}




\section{REVISTA VIRTUAL VIA INVENIENDI ET |UDICAND|}

"CAMINO DEL HALLAZGO Y DEL JUICIO"

http://viei.usta.edu.co/ E-MAIL: revistainveniendi@usantotomas.edu.co

Es necesario que se haga una breve referencia a los derechos de los extranjeros desde el marco constitucional y legal, para luego poder entrar a comprender el papel de la jurisprudencia en el avance de la garantía de los derechos de este colectivo.

El punto de partida que refleja la voluntad del Estado español de conceder y garantizar a los extranjeros derechos y deberes fundamentales es el artículo 13.1 de la Constitución Española (en adelante C.E), pues indica que los extranjeros gozarán en España de las libertades públicas que consagra el título I en los términos que establecen los tratados internacionales y la ley. Así mismo en el numeral 2 precisa que solamente los españoles serán titulares de los derechos reconocidos en el artículo 23. El título I de la Constitución al que se hace referencia hace alusión a los derechos y deberes fundamentales, como se verá con mayor precisión en seguida, en tanto que la exclusión efectuada sobre el artículo 23 se refiere al derecho al sufragio activo y pasivo, que por considerarse un derecho político sólo puede ser ejercitado por los nacionales. ${ }^{2}$

Pese a lo anterior, si se realiza una lectura del artículo 14 constitucional, se notará sin mayor esfuerzo que al parecer la igualdad ante la Ley se aplica de manera exclusiva a los españoles, pues su redacción no podría ser más clara y tajante. Sin embargo, aquel despropósito no puede afirmarse, pues la jurisprudencia del Tribunal Constitucional marcando una línea interpretativa en este aspecto, y en concreto en el caso de los extranjeros, ha determinado sin mayor titubeo que esto no debe ser entendido de manera restrictiva, sino que armonizando dicha norma con el artículo 13, se tendrá que

\footnotetext{
${ }^{2}$ Sobre este punto debe hacerse una aclaración, dado que frente a esta regla constitucional se presenta una excepción consistente en permitir que los ciudadanos europeos puedan ejercitar este derecho político en las elecciones municipales. Dicha regla constitucional fue flexibilizada en virtud de la Decisión $1^{\circ}$ de 1992, emitida por el Tribunal Constitucional, en la que se analiza la adecuación del artículo 8.B del Tratado de Maastricht con el artículo 13 de la Constitución Española, apartado 2, según el cual este derecho era exclusivo de los españoles, salvo que existiera reciprocidad en virtud de un tratado. De la confrontación mencionada se derivó la reforma constitucional insertada, gracias a la cual los ciudadanos de la Unión que no sean nacionales y que residan en el territorio español tendrán derecho al sufragio pasivo en las elecciones municipales.
} 


\section{REVISTA VIRTUAL VIA INVENIENDI ET |UDICAND|}

"CAMINO DEL HALLAZGO Y DEL JUICIO"

http://viei.usta.edu.co/ E-MAIL: revistainveniendi@usantotomas.edu.co

interpretar que la igualdad ante la Ley por encontrarse dentro del título dedicado a los derechos y deberes fundamentales, será aplicado también a los extranjeros. ${ }^{3}$

Es importante tener en cuenta, que a lo largo del título que se ocupa de los derechos y de los deberes fundamentales, no se halla unidad lingüística en determinar los sujetos activos o pasivos de la norma, lo cual, se refleja en el mundo de los derechos como el mayor o menor grado de ejercicio por parte de los sujetos. Es claro que algunos de los derechos son garantizados de manera homogénea a "todos" los individuos atendiendo a su condición de seres humanos, y otros son otorgados a los "ciudadanos", también por el hecho de serlo, es decir por ajustarse al "ius soli", al "ius sanguini" y observar las disposiciones de doble nacionalidad y naturalización ratificados con otros Estados, tal y como lo dispone el artículo 11 de la C.E.

Cabe anotar antes de continuar con el listado de los derechos en los que se maneja el vocablo "todos", o "los españoles, que en el artículo 9०, que hace parte del título preliminar se enuncia que: "los ciudadanos y los poderes públicos están sujetos a la Constitución y al resto del ordenamiento jurídico"4. Si bien, esta norma obliga en principio a los españoles al cumplimiento estricto del ordenamiento jurídico, son todos los individuos que se encuentren en el territorio español, los obligados a respetar el orden y las leyes del Estado, en este sentido, los extranjeros y por su puesto los inmigrantes deberán cumplir con dichos preceptos normativos.

El parágrafo segundo del artículo se presta para contradicciones, pues de un lado, defiere a la actividad de los poderes públicos la promoción de las condiciones de igualdad y libertad de "los individuos", en sentido genérico, y a pocos renglones determina que se eliminarán los obstáculos que pudieran existir para el ejercicio de la participación de los ciudadanos en la vida política, económica, cultural y social.

\footnotetext{
${ }^{3}$ España, Tribunal Constitucional (1984, Noviembre), Sentencia 107, Sala Segunda, Fundamento Jurídico No. 3

${ }^{4}$ España (2006), segunda reimpresión, Constitución Española de 1978, Madrid, Tecnos.
} 
REVISTA VIRTUAL VIA INVENIENDI ET IUDICANDI

"CAMINO DEL HALLAZGO Y DEL JUICIO"

http://viei.usta.edu.co/ E-MAIL: revistainveniendi@usantotomas.edu.co

Pareciere entonces que algunas prescripciones normativas son extensivas a los individuos, personas, o seres humanos en general, y otras no lo son tanto, por lo que a lo largo de los comentarios de los artículos veremos si las exclusiones o diferenciaciones atienden a motivos razonables y suficientes, o si por el contrario es una aplicación lineal del clásico concepto de la ciudadanía. ${ }^{5}$

Los artículos $15,16,17,18,20,21,24,25,27,28^{6}$, que hacen parte de la subclasificación de los derechos fundamentales y de las libertades públicas, al emplear el vocablo "todos" sugiere que los derechos consagrados en estas normas son de aplicación extensiva a los individuos en general, no se efectúa por tanto una limitación concreta, ni se restringe el ejercicio de estos derechos, por lo que no resulta aventurado concluir que los extranjeros migrantes se encuentran cobijados por dichas garantías. El espíritu de la Constitución al parecer, pretendía universalizar la aplicación de estos derechos y no contempló la necesidad de que los titulares de los mismos tuvieran que ser ciudadanos para poder disfrutar de estos en condiciones de igualdad. No ocurre lo mismo con otro grupo de derechos que a partir de la consagración constitucional, plantean una restricción en razón al estatus de ciudadanía, estos son, los derechos contenidos en los artículos 19, 23, y $29^{7}$.

Es relevante hacer especial referencia a la libertad de residencia y de circulación en el territorio español, toda vez que, es precisamente este derecho el que cumple efecto amplificador de los demás derechos en lo que respecta a los extranjeros. Es exclusivo

\footnotetext{
${ }^{5}$ De Lucas J. (2001) Las condiciones de un pacto social sobre la inmigración. Inmigración y derechos humanos, Zaragoza, Mira, Página 52.

${ }^{6}$ Derecho a la vida, la libertad ideológica, religiosa y de culto, derecho a la libertad, habeas corpus, debido proceso, derecho al honor, a la intimidad personal y familiar y la propia imagen, la inviolabilidad del domicilio, libertad de pensamiento, producción y creación literaria, artística, científica y técnica, libertad de cátedra, libertad de información, derecho a la reunión pacífica, derecho de asociación, derecho a la tutela judicial efectiva, aplicación del principio de legalidad en la ley penal y en los procedimientos administrativos, derecho a la educación, derecho a la sindicación, derecho de huelga.

${ }^{7}$ Libertad de residencia y circulación dentro del territorio nacional, derecho a la participación política a través del ejercicio del sufragio activo y pasivo, el derecho al ejercicio de los cargos públicos y el derecho de petición.
} 
REVISTA VIRTUAL VIA INVENIENDI ET IUDICANDI

"CAMINO DEL HALLAZGO Y DEL JUICIO"

http://viei.usta.edu.co/ E-MAIL: revistainveniendi@usantotomas.edu.co

de los españoles ejercitarlo, por tanto, podrán determinar su lugar de residencia y movilizarse sin intervención del Estado por el territorio.

La base para la limitación de la entrada de los extranjeros al Estado español se encuentra precisamente en este artículo, y de acuerdo con el, se ha estructurado la normatividad sobre permisos de residencia y expedición de visados. Vale la pena mencionar que el derecho internacional otorga a los Estados la posibilidad de que a través de la normatividad interna regulen los aspectos relacionados con esto, y ni en la Declaración Universal de Derechos Humanos (en adelante DUDH) de 1948, ni en el Pacto Internacional de Derechos Civiles y Políticos (en adelante PIDCP) de 1966, se consagra ningún derecho a "inmigrar" de parte de los extranjeros a otros países, quedando de este modo a discrecionalidad absoluta del Estado y al ejercicio de su soberanía la regulación de estos aspectos. De hacer un examen riguroso de este derecho habría que examinar todos y cada uno de los artículos de los diferentes instrumentos internacionales que lo consagran. ${ }^{8}$

\footnotetext{
${ }^{8}$ Es así como en la Declaración Universal de 1948 su artículo 13 dispone que "Toda persona tiene el derecho a circular libremente y a elegir su residencia en el territorio de un Estado", como puede verse de la redacción de este primer numeral al parecer hay amplitud en la libertad de la que goza el individuo para elegir cual ha de ser el lugar en el que desee asentarse, sin embargo el numeral 2 indica el derecho de las personas a salir de cualquier país, incluido el de su nacionalidad y así mismo a regresar a este. Esta segunda parte de la redacción del artículo ilustra un poco más la cuestión y deja en claro que a la luz de la DUDH existe un derecho a emigrar. No obstante ello parece estar incompleto el derecho, toda vez que los movimientos migratorios son de doble flujo ${ }^{8} \mathrm{y}$ si bien se reconoce el derecho a salir de un Estado, incluido el propio, es lógico y consecuente que el individuo tendrá que desplazarse a otro lugar, lo que evidentemente no es una libertad ejercitable de los extranjeros.
}

El Pacto Internacional de Derechos Civiles y Políticos ofrece en este sentido un poco mas de claridad, en razón a que en el artículo 12, parágrafos 1, 2, 3 y 4 establece que 1. "Toda persona que se halle legalmente en el territorio de un Estado tendrá derecho a circular libremente por él, y a escoger libremente en él su residencia.” 2. "Toda persona tendrá derecho a salir libremente de cualquier país, incluso del propio". 3. "Los derechos antes mencionados no podrán ser objeto de restricciones salvo cuando éstas se hallen previstas en la ley, sean necesarias para proteger la seguridad nacional, el orden público, la salud o la moral públicas o los derechos y libertades de terceros, y sean compatibles con los demás derechos reconocidos en el presente Pacto". 4. "Nadie podrá ser arbitrariamente privado del derecho a entrar en su propio país”. 


\section{REVISTA VIRTUAL VIA INVENIENDI ET |UDICAND|}

"CAMINO DEL HALLAZGO Y DEL JUICIO"

http://viei.usta.edu.co/ E-MAIL: revistainveniendi@usantotomas.edu.co

Al examinar la sección 2 dedicada a los "Derechos y deberes de los ciudadanos", llama la atención el artículo 31 de la C.E. el cual determina que "todos contribuirán al sostenimiento de los gastos públicos de acuerdo con su capacidad económica mediante un sistema tributario justo inspirado en los principios de la igualdad y progresividad que, en ningún caso tendrán alcance confiscatorio".

Vale anotar sobre este punto que el 15 de la Ley 8 de $2000^{9}$, establece la sujeción general por parte de los extranjeros al sistema impositivo de la misma forma como lo hace con los españoles. La principal crítica que puede formularse a este precepto normativo radica en que en el texto de la misma no se sujeta a las condiciones de la legalidad de la persona, es decir, no entra a examinar si se encuentra en posesión de su permiso de residencia, o por el contrario la redacción de la norma es amplia, y pareciere que los extranjeros en situación jurídica de indocumentados o de irregularidad deben también contribuir con el sostenimiento del Estado. De ser esto así se establecería una sanción adicional a estos individuos, toda vez que se encuentran en un limbo jurídico respecto al acceso de derechos prioritarios para su subsistencia, pero además como agravante de ello, los ingresos derivados de sus trabajos por lo general precarios se ven disminuidos en razón al pago de las contribuciones fiscales.

No resulta políticamente muy correcto entonces pretender recibir aportes económicos, de quienes se hallan en invisibilidad jurídica, la invisibilidad o visibilidad de estos sujetos debería ser homogénea para todas sus relaciones con el Estado, en el sentido en el que no verán jamás retribuidos en su beneficio, los recursos que por obligación legal deberán entregar para el correcto funcionamiento del Estado y por su puesto la garantía de los derechos.

\footnotetext{
${ }^{9}$ España, Juan Carlos I, Cortes Generales (2000, 22 de diciembre) Ley 8 de 22 de diciembre de 2000, de reforma de la Ley Orgánica 4 de 11 de enero de 2000, sobre derechos y libertades de los extranjeros en España y su integración social, BOE Número 307, de 23 de diciembre de 2000, Madrid.
} 


\section{REVISTA VIRTUAL VIA INVENIENDI ET |UDICAND|}

"CAMINO DEL HALLAZGO Y DEL JUICIO"

http://viei.usta.edu.co/ E-MAIL: revistainveniendi@usantotomas.edu.co

Continuando con los derechos y deberes del ciudadano, los artículos 32, 33, 34 y $38^{10}$, prescriben derechos de manera genérica, dando así mismo amplitud en su aplicación. Si bien esto es así en los artículos que se han comentado hasta ahora, no puede perderse de vista que el sustento a ello se halla precisamente en el artículo13 antes anotado y que considera que los extranjeros gozarán de las libertades públicas que garantiza el título primero pero de acuerdo con los términos que fija la Ley interna y los tratados internacionales.

El derecho al trabajo merece una precisión especial, toda vez que el artículo 35 dispone que "Todos los españoles tienen el deber de trabajar y el derecho al trabajo...". Como puede verse se encuentra restringido a los ciudadanos, aspecto comprensible desde la óptica de las escasas ofertas laborales que en el mercado se presentan y desde la vocación natural del Estado a preservar y promover las circunstancias para la efectividad de la garantía de sus miembros. No obstante, es precisamente el tema laboral una de las causas por las que se ha agudizado el tema de la inmigración. Según algunos reportes que evidencian estadísticas en este tema se afirma, que la fuerza de trabajo del inmigrante es de relevancia para el mantenimiento de la economía española, sobre todo en aquellos oficios que no quieren ser desempeñados por los mismos nacionales. Sin embargo, las condiciones de trabajo de los inmigrantes y en especial de aquellos que se encuentran indocumentados, es precaria y sin el ánimo de ser redundante se intensifica la ausencia de derechos en la ausencia del derecho al trabajo. ${ }^{11}$

Así las cosas, los derechos que en principio deben considerarse de ejercicio pleno, son aquellos que deben ser reconocidos a toda persona sin tener en consideración su

\footnotetext{
${ }^{10}$ Se trata del derecho a contraer matrimonio con plena igualdad jurídica, derecho a la propiedad privada y a la herencia, derecho de fundación para fines de interés general.

${ }^{11}$ Organización Internacional del Trabajo OIT, (2004) "En busca de un compromiso equitativo para los trabajadores migrantes en la economía globalizada”, Conferencia Internacional del Trabajo, 92 ${ }^{\mathrm{a}}$ reunión, 2004, párr. 140. http://www.ilo.org/wcmsp5/groups/public/---dgreports/---dcomm/documents/meetingdocument/kd00096es.pdf.
} 


\section{REVISTA VIRTUAL VIA INVENIENDI ET |UDICAND|}

"CAMINO DEL HALLAZGO Y DEL JUICIO"

http://viei.usta.edu.co/ E-MAIL: revistainveniendi@usantotomas.edu.co

nacionalidad, lo que resulta ser coincidente con lo dispuesto por el artículo 10.1 del texto constitucional. Estos derechos no son otros que los concebidos como derechos humanos aceptados universalmente, por hacer parte integral de la dignidad humana o ser derechos de personalidad, dentro de los cuales se debe hacer mención a la vida, a la integridad física y moral, libertad ideológica, religiosa y de culto, derecho a la libertad personal, seguridad jurídica, derecho al honor, intimidad personal y familiar, la propia imagen, entre otros. ${ }^{12}$

En cuanto a los principios rectores de la política social y económica (capítulo III de la C.E. ${ }^{13}$ ) la Carta dispone que los poderes públicos asegurarán la protección social económica y jurídica de la familia (artículo 39), aspecto que en directa conexión con el derecho a contraer matrimonio ilustra que los extranjeros se encuentran también cobijados por esta norma. De la misma forma ocurre con las disposiciones subsiguientes relativas a la promoción de las condiciones favorables del desarrollo social y económico y algunos otros derechos económicos, sociales y culturales como los contenidos en los artículos, 40,43, 44, 45, 46, 48, 49 y $51 .{ }^{14}$

Sin embargo al igual que como fue puesto de presente en lo relacionado a los derechos, libertades, y derechos y deberes, existen algunos artículos que prevén los beneficios única y exclusivamente a los ciudadanos españoles, dentro de los cuales se pueden enunciar los previstos en los artículos $41,42,47$ y $50^{15}$.

\footnotetext{
${ }^{12}$ Estrada Carrillo V. (1993) Extranjería, comentarios y análisis prácticos. Madrid: Trivium.

${ }^{13}$ Aspecto que no será tratado con mayor profundidad en este artículo, toda vez que hace parte de otro trabajo complementario que se dedica en exclusiva al análisis de los derechos sociales.

${ }^{14}$ Versan sobre la protección social, jurídica y económica de la familia, la creación de las condiciones para el progreso social y económico, la protección de la salud, la promoción de la cultura, la ciencia, la investigación científica y la técnica, medio ambiente adecuado, utilización racional de los recursos naturales, conservación del patrimonio histórico, cultural y artístico de los pueblos, participación de la juventud, previsión, tratamiento y rehabilitación de las personas con discapacidad física, sensorial o cognitiva.

${ }^{15}$ El mantenimiento del régimen de la seguridad social, el acceso y la asistencia a las prestaciones sociales, la salvaguarda de los derechos económicos y sociales de los trabajadores españoles en el exterior, el derecho a la vivienda digna.
} 


\section{REVISTA VIRTUAL VIA INVENIENDI ET |UDICAND|}

"CAMINO DEL HALLAZGO Y DEL JUICIO"

http://viei.usta.edu.co/ E-MAIL: revistainveniendi@usantotomas.edu.co

Lo anterior evidencia que respecto de los derechos consagrados en la Constitución existen por decirlo de un algún modo grados de titularidad, es decir algunos derechos se predican en exclusiva respecto de los ciudadanos españoles, y otros tantos se hacen extensivos a los extranjeros, quedando éstos últimos en todo caso sometidos al desarrollo legal y a la aplicación de la norma internacional adoptada por el Estado. ${ }^{16}$ Por lo que resulta absolutamente obvia la conclusión según la cual a partir del estatus de ciudadanía no es posible predicar igualdad, toda vez que la misma, es un elemento característico de la construcción de identidad nacional y de la relación de pertenencia del individuo con el territorio en cuanto a su origen.

\section{El avance en la garantía de los derechos civiles: un camino labrado por la jurisprudencia.}

El papel de la jurisprudencia se pude catalogar como protagonista en lo que se refiera al alcance y a la interpretación de los derechos de los extranjeros, en el Estado español, sin embargo esta no ha hecho un impacto homogéneo en todos los momentos en los que el mismo se ha dado a la tarea de regular a través de las leyes y reglamentos las condiciones para el disfrute de los derechos de este colectivo.

Tal y como se anotó en el apartado anterior, la Constitución española fija algunas coordenadas generales sobre los derechos que se pueden ser ejercitados por los extranjeros, sin embargo la misma letra del texto permite que el legislador tenga un amplio campo de configuración de estas garantías, lo que en la historia del derecho de extranjería se ha realizado a través de las leyes 7 de $1985,{ }^{17} 4$ de $2000^{18}$ y 8 de $2000^{19}$, con sus correspondientes reglamentos.

\footnotetext{
${ }^{16}$ De Lucas J (1994) El desafío de las fronteras, derechos humanos y xenofobia dentro de una sociedad plural, Madrid, Ediciones temas de hoy.

${ }^{17}$ España, Juan Carlos I, Cortes Generales (1985, 1 de abril ) Ley 7 de 1 de abril de 1985, sobre derechos y libertades de los extranjeros en España, BOE Número 0158, de 3 de julio de 1985, Madrid.

${ }^{18}$ España, Juan Carlos I, Cortes Generales (2000, 11 de enero) Ley 4 de 11 de enero de 2000 sobre derechos y libertades de los extranjeros en España y su integración social, BOE Número 10, de 12 de enero de 2000, Madrid.
} 


\section{REVISTA VIRTUAL VIA INVENIENDI ET |UDICAND|}

"CAMINO DEL HALLAZGO Y DEL JUICIO"

http://viei.usta.edu.co/ E-MAIL: revistainveniendi@usantotomas.edu.co

El manejo legislativo que se ha dado al tema de los derechos de los extranjeros no ha sido en todos los casos el mas favorable para con este colectivo, y algunos de los planteamientos normativos pueden considerarse mas restrictivos que otros, es así como la última reforma legislativa en esta materia, adelantada por la Ley 8 de 2000, limita un importante grupo de derechos que posteriormente es reivindicado con la tarea del Tribunal Constitucional Español en sus últimas sentencias.

\section{a. Derecho a la igualdad}

La sentencia del Tribunal Constitucional (en adelante STC) 107 de $1984^{20}$, inaugura las interpretaciones en materia de extranjería y establece un concepto bien definido en lo que se refiere al derecho a la igualdad de los extranjeros. En sus fundamentos jurídicos anota la necesidad de que se realice una interpretación sistemática del artículo 14 constitucional, toda vez que de la lectura simple de esta norma, el derecho a la igualdad parece ser solo predicable de manera exclusiva de los españoles. Anota que la disposición debe examinarse a la luz del 13 de la misma Constitución, el cual consagra, que los extranjeros podrán ser legítimos titulares de los derechos contenidos en el título dedicado a los derechos y deberes fundamentales (Título I), en atención a las normas que desarrolle el poder legislativo, y de las disposiciones de los instrumentos internacionales que han sido debidamente ratificados por el Estado.

En esta sentencia se teoriza sobre tres grupos de derechos que se derivan de la norma en estudio, es decir el artículo 13 de la C.E. Los primeros aquellos que hacen parte de la dignidad del individuo y que se deben garantizar de manera genérica, estos serán los

\footnotetext{
${ }^{19}$ España, Juan Carlos I, Cortes Generales (2000, 22 de diciembre) Ley 8 de 2000 , Ley 8 de 22 de diciembre de 2000, de reforma de la Ley Orgánica 4 de 11 de enero de 2000, sobre derechos y libertades de los extranjeros en España y su integración social, BOE Número 307, de 23 de diciembre de 2000, Madrid.

${ }^{20}$ España, Tribunal Constitucional (1984, noviembre), Sentencia Tribunal Constitucional 107, sala segunda, Madrid.
} 


\section{REVISTA VIRTUAL VIA INVENIENDI ET |UDICAND|}

"CAMINO DEL HALLAZGO Y DEL JUICIO"

http://viei.usta.edu.co/ E-MAIL: revistainveniendi@usantotomas.edu.co

del título I del texto constitucional. Los segundos, aquellos que por ser derechos políticos se reconocen solamente a los españoles, tal como ocurre con el artículo 23 que contempla el sufragio activo y pasivo, y el tercero, aquellos derechos que se regularán por medio de una ley, y los que provienen de los tratados internacionales ratificados por España, siendo este último grupo el centro de gravedad de la problemática de la asignación de derechos que hace el legislador a los extranjeros con ocasión a la expedición de una ley.

De la mano de lo anterior una de las precisiones más relevantes que efectúa la providencia radica en aclarar que el hecho de que las interpretaciones se realicen a la luz de los tratados internacionales, no implica que tales derechos se encuentren desconstitucionalizados, sino que por el contrario, gozan de la protección constitucional y requieren de configuración legal. ${ }^{21}$

Adicionalmente se anota que todos estos derechos sin excepción requieren de la existencia de una Ley, la cual deberá determinar el contenido del derecho, y que el legislador examinará qué derechos pueden ser de titularidad de los extranjeros en las mismas condiciones que los disfrutan los españoles, de modo que se pueda alcanzar eventualmente por esta vía la igualdad entre los españoles y los extranjeros.

Se anota además, que esto no ocurre precisamente con aquella categoría de derechos que pertenecen al ser humano por el solo hecho de serlo, entendiendo éste como el primer grupo de derechos que son universales, se reconocen a todas las personas y se encuentran vinculados con la dignidad humana, tales como la vida, la integridad física y moral (artículo 15 C.E), la libertad ideológica (artículo 16 C.E), la intimidad (artículo 18 C.E.) entre otros, los cuales no admiten de acuerdo al T.C. un trato diferenciado.

\footnotetext{
${ }^{21}$ Ibídem, Fundamento Jurídico No. 3
} 


\section{REVISTA VIRTUAL VIA INVENIENDI ET |UDICAND|}

"CAMINO DEL HALLAZGO Y DEL JUICIO"

http://viei.usta.edu.co/ E-MAIL: revistainveniendi@usantotomas.edu.co

Es así como de acuerdo con las normas constitucionales y la interpretación dada por el T.C, los derechos y deberes fundamentales del título I, no son derechos de aplicación inmediata, en tanto requieren de la existencia de una norma para su efectividad. En la misma sentencia, se anota que no es posible que todos los derechos contenidos en el título en mención pertenezcan por igual a todos los individuos incluidos los extranjeros, toda vez, que existe un grupo de ellos que se halla restringido al ejercicio de los ciudadanos, como ocurre en el caso del artículo 23 de la Constitución, que contempla el derecho al sufragio pasivo y activo y la participación en los asuntos públicos. La Corporación señala igualmente que la valoración acerca de la protección del derecho deberá realizarse caso por caso, analizando los derechos que se encuentren en debate.

De la anterior sentencia puede inferirse entonces, que plantea una tendencia un poco contradictoria pues de un lado deja claro que no sería adecuado interpretar de manera escueta el artículo 14 constitucional y entender el derecho de igualdad ante la Ley como un derecho de mera ciudadanía, pero del otro, sujeta los derechos y deberes fundamentales al arraigado concepto clásico de ciudadanía y al principio de legalidad por encima del de constitucionalidad, lo que no resultaría ser tan negativo si se tiene en cuenta que para la fecha de expedición de la sentencia no existía un grueso volumen de inmigración como el de la actualidad, y que es el primer pronunciamiento que enfrenta estos retos con un instrumento jurídico prácticamente nuevo, como lo era para ese entonces la Constitución de 1978, que defendía un rescatado concepto de democracia y sin duda una nueva y oxigenada identidad nacional de ciudadano.

A su turno la STC 242 de 1994, en su fundamento jurídico No. 4, ${ }^{22}$ complementa el anterior pronunciamiento y amplía la noción de lo que se debe entender por igualdad entre los ciudadanos españoles y los extranjeros. Afirma pues, que el legislador se encuentra investido de plena facultad para imponer los límites en virtud de la

\footnotetext{
${ }^{22}$ España, Tribunal Constitucional (1994, agosto), Sentencia Tribunal Constitucional 242 de 1994, sala primera, Madrid.
} 
REVISTA VIRTUAL VIA INVENIENDI ET IUDICAND\|

"CAMINO DEL HALLAZGO Y DEL JUICIO"

http://viei.usta.edu.co/ E-MAIL: revistainveniendi@usantotomas.edu.co

interpretación del artículo 13 de la Constitución, como por ejemplo, el pleno ejercicio de los derechos políticos. Pese a ello, no deja de reconocer que esos límites establecidos por el legislativo tienen a su vez también otros límites que atienden al respeto de la dignidad humana, y los derechos que garantizan este valor atendiendo por su puesto a la norma del artículo 10.1 y 10.2 de la Constitución. ${ }^{23}$

Del mismo modo se resalta la importancia de respetar las disposiciones contenidas en los tratados internacionales sobre derechos, al referirse concretamente al PIDCP, en aplicación de los artículos 12 y $13^{24}$ que establecen, las condiciones que deberán ser acatadas por los Estados para la procedencia de la expulsión de los extranjeros que habitan o residen en condiciones de ilegalidad al interior de un país. ${ }^{25}$ Como pude verse dicha providencia da un poco mas de claridad sobre el papel de la dignidad

\footnotetext{
${ }^{23}$ El artículo 10.1 de la Constitución dispone que la dignidad de la persona es inviolable y a su turno el 10.2 que los derechos fundamentales consagrados en el título I de la misma se interpretarán con arreglo a la Declaración Universal de Derechos Humanos y a los tratados internacionales sobre la materia que hayan sido ratificados por España. Sobre este particular es pertinente tener en cuenta la fricción que se presenta entre la soberanía del Estado y el cumplimiento y la garantía de los no solo fundamentales, sino humanos, tal y como lo anota el profesor Juan Antonio Carrillo Salcedo en su obra "Soberanía de los Estados y derechos humanos en el derecho internacional contemporáneo", al indicar que " la acción del orden internacional en relación con los derechos humanos ha de llevarse a cabo en un mundo de Estados soberanos, lo que explica la tensión dialéctica existente entre estos dos principios constitucionales del orden internacional: la soberanía de los Estados por un lado, y el reconocimiento y protección internacionales de los derechos humanos, por el otro ${ }^{23}$. Si bien los Estados tienen la posibilidad de regular los aspectos internos que tengan que ver con la seguridad del Estado y el orden al interior de sus fronteras, tal y como ocurre con los movimientos migratorios, también es cierto que existe la limitación a esta potestad en virtud de la defensa de los derechos humanos y sobre todo de la dignidad del individuo, es así como la potestad legislativa deberá obrar de modo tal que no llegue a conculcar este principio democrático.
}

${ }^{24}$ El Artículo 12 dispone: 1. "Toda persona que se halle legalmente en el territorio de un Estado tendrá derecho a circular libremente por él y a escoger libremente en él su residencia. 2. Toda persona tendrá derecho a salir libremente de cualquier país, incluso en el propio. 3. Los derechos antes mencionados no podrán ser objeto de restricciones salvo cuando estas se hallen previstas en la Ley, sean necesarias para proteger la seguridad nacional, en el orden público, la salud o la moral públicas o los derechos libertades de terceros, y sean compatibles con los demás derechos recocidos en el presente pacto. 4. Nadie podrá ser arbitrariamente privado del derecho a entrar en su propio país.

En su lugar el artículo 13 dispone que "Los derechos antes mencionados no podrán ser objetos de restricciones salvo cuando éstas se hallen previstas en la Ley, sean necesarias para proteger la seguridad nacional, el orden público, la salud, o la moral públicas o los derechos y libertades de terceros, y sean compatibles con los demás derechos reconocidos en el presente pacto.

${ }^{25}$ Caso en el que se plantea una pena de muerte, y la necesidad de efectuar la extradición del sindicado a los E.U.A, el cual no se autoriza, por considerarse que aquel periodo en el que se encuentra en el corredor de la muerte. 


\section{REVISTA VIRTUAL VIA INVENIENDI ET |UDICAND|}

"CAMINO DEL HALLAZGO Y DEL JUICIO"

http://viei.usta.edu.co/ E-MAIL: revistainveniendi@usantotomas.edu.co

humana en la asignación de los derechos de los extranjeros y en la importancia de los tratados de derechos humanos en este mismo estadio.

\section{b. Derecho a la libertad y a la seguridad personal}

El catálogo de derechos se amplía con el fallo STC 115 de $1987^{26}$, según el cual, la libertad y seguridad personal son consideradas como derechos inherentes a la condición humana, y por tanto, de titularidad compartida por parte de los nacionales y de los extranjeros en condiciones de igualdad, sin que exista motivo razonable para la procedencia de una discriminación. Sobre el particular a la fecha no han existido otros pronunciamientos que gocen de relevancia.

\section{c. Derecho a la tutela judicial efectiva}

Sobre este punto la STC 99 de $1985^{27}$, determina que el derecho a la tutela judicial efectiva ${ }^{28}$ es de aquellos derechos que pueden considerarse como de la esencia misma del ser humano, por tanto, será extensivo en su aplicación a la población extranjera. Para llegar a esta interpretación se sirve de lo dispuesto por la DUDH, por el PIDCP y el Convenio de $\mathrm{Roma}^{29}$. Aspecto que es modificado dramáticamente con posterioridad con ocasión a la normatividad desarrollada en las leyes 4 de 2000 y 8 de 2000, tal y como se ha señalado antes. ${ }^{30} \mathrm{Y}$ que más adelante propicia el reciente pronunciamiento jurisprudencial que retrotrae estos efectos.

\footnotetext{
${ }^{26}$ España, Tribunal Constitucional (1987 julio). STC 115. Madrid, Fundamento Jurídico No. 1

${ }^{27}$ España, Tribunal Constitucional (1985 noviembre). STC 99. Madrid, Fundamento Jurídico No. 4

${ }^{28}$ Sobre este mismo derecho cabe anotar que la Sentencia de 9 de mayo del Tribunal Supremo, acota igualmente que todas las personas tienen el derecho a la tutela judicial efectiva.

${ }^{29}$ Conocido como Convenio Europeo de Derechos Humanos, firmado en Roma el 4 de noviembre de 1950, y entrado en vigor el 3 de septiembre de 1953, se constituye para la salvaguardia de los derechos humanos y las libertades fundamentales.

${ }^{30}$ La Ley 8 de 2000, que se encarga de reformar la Ley 4 de 2000, contempla una regresiva garantía en lo que se refiere al derecho a la tutela judicial efectiva en cabeza de los extranjeros, pues restringe este derecho a aquellos inmigrantes que se encuentren dentro del territorio nacional con su documentación en regla, es decir bajo el llamado estatus de legalidad.
} 


\section{REVISTA VIRTUAL VIA INVENIENDI ET |UDICAND|}

"CAMINO DEL HALLAZGO Y DEL JUICIO"

http://viei.usta.edu.co/ E-MAIL: revistainveniendi@usantotomas.edu.co

Otro de los precedentes que contiene un importante pronunciamiento sobre este particular es la STC 71 de $1988^{31}$, pues se refiere al derecho de defensa y a la asistencia de un letrado o intérprete en el caso de juicio. Dicho pronunciamiento determina que no obstante tal derecho no se encuentre consagrado de manera concreta y expresa en la constitución, debe hacerse extensivo del derecho de defensa, teniendo en cuenta la importancia que comporta para un individuo al que se está procesando, el hecho de entender la situación jurídica que lo vincula y las repercusiones que esto comporta para la eficacia del derecho a la defensa. En refuerzo de esto, se puede citar la STC 188 de $1991^{32}$, la cual como elemento adicional a la anterior, recoge el pronunciamiento del TEDH, en el caso Cuscani Vs. Reino Unido de septiembre de $2002 .^{33}$

Dado que el derecho de defensa tiene estrecha relación con el de la tutela judicial efectiva, la STC 95 de $2003^{34}$ amplia el espectro de protección del mismo y señala como elemento integrante del núcleo fundamental de este derecho la asistencia jurídica gratuita para los extranjeros. Sobre este punto se anota que en los eventos en los que los individuos no cuenten con los recursos económicos para realizar su adecuada defensa, podrán acceder a la asistencia jurídica gratuita, siempre y cuando sea acreditada su precariedad económica.

El pronunciamiento cataloga este derecho como prestacional y susceptible de definición por parte del legislador, el cual determinará en que eventos y en que tipo de procesos será efectiva la garantía. No obstante, señala que existe un núcleo de este derecho que resulta indisponible y que se encuentra constitucionalmente establecido. En este

\footnotetext{
${ }^{31}$ España, Tribunal Constitucional (1988 noviembre) STC 7, Madrid, fundamento Jurídico No. 4

${ }^{32}$ España, Tribunal Constitucional (1991 octubre) STC 188, Madrid, fundamento Jurídico No. 2

${ }^{33}$ En este caso el TEDH sostuvo que los jueces son garantes de la defensa adecuada de los acusados y en este sentido deberán tener en cuenta la imposibilidad de comprensión de aquellos que deben ser defendidos en una lengua diferente a su lengua nativa, por tanto es preciso que para que el derecho a la tutela judicial efectiva se materialice se empleen los servicios de un intérprete en estos casos.

${ }^{34}$ España, Tribunal Constitucional ( 2003 mayo) STC 95, fundamentos Jurídicos Nos. 3 y 4
} 


\section{REVISTA VIRTUAL VIA INVENIENDI ET |UDICAND|}

"CAMINO DEL HALLAZGO Y DEL JUICIO"

http://viei.usta.edu.co/ E-MAIL: revistainveniendi@usantotomas.edu.co

sentido, vale la pena tener en cuenta que el artículo 24 de la Constitución preceptúa que: "Todas las personas tienen derecho a obtener la tutela efectiva de los jueces y tribunales, en ejercicio de sus derechos e intereses legítimos, sin que, en ningún caso, pueda producirse indefensión".

Al parecer la redacción del artículo referenciado permite que sin excepción los individuos puedan acceder al derecho a la tutela judicial efectiva, sin que medien consideraciones adicionales y diferentes a las de ser simple "ser humano". Así mismo, se refuerza la garantía al establecerse la prohibición de que en cualquier caso puedan propiciarse circunstancias de inferioridad para con la persona involucrada en el litigio. En consonancia con esto, la jurisprudencia ha establecido que los extranjeros son titulares de este derecho y se les garantizará en las mismas condiciones que se hace para con los españoles ${ }^{35}$. Más adelante se trata como este derecho fue desconocido por la Ley 8 de 2000 y posteriormente reivindicado.

La STC 236 de 7 de noviembre de $2007^{36}$ (una de las más recientes y que de la que se hará referencia más adelante, toda vez que trata muchos otros derechos), examina un cargo de inconstitucionalidad que se formula respecto del artículo 22 apartado 2 de la Ley 8 de 2000 relativo a la asistencia jurídica gratuita. La ley de extranjería vigente circunscribía a los residentes legales que no contaran con los recursos económicos suficientes, el derecho a esta asistencia en todo tipo de litigio, lo que dejaba excluidos a los extranjeros en situación jurídica de irregularidad. En su lugar, estos últimos sí ostentaban dicha garantía en los asuntos administrativos y judiciales que tuvieran que ver con la denegación de su entrada, su devolución o su expulsión del territorio español. Para el Tribunal la exclusión de los extranjeros indocumentados no resultaba ser

\footnotetext{
${ }^{35}$ Una de las sentencias mas recientes que tratan este mismo tema es la Sentencia Tribunal Constitucional 145 de mayo de 2006.

${ }^{36}$ Resuelve el recurso de inconstitucionalidad interpuesto por una letrada del Parlamento de Navarra, en contra de varios artículos de la Ley 8 de 2000.
} 


\section{REVISTA VIRTUAL VIA INVENIENDI ET |UDICAND|}

"CAMINO DEL HALLAZGO Y DEL JUICIO"

http://viei.usta.edu.co/ E-MAIL: revistainveniendi@usantotomas.edu.co

razonable, y comprometía su ejercicio al derecho a la tutela judicial efectiva. Indica además que el legislador se excedió en sus potestades y tocó un derecho que hace parte de la esencia misma del individuo y que se vincula con la dignidad humana.

Como puede verse sin bien la jurisprudencia previa a la expedición de la Ley 8 de 2000 fijaba unos marcos frente a este derecho, la norma hizo caso omiso a los pronunciamientos y este derecho se vio limitado durante muchos años, hasta que en la reciente providencia citada se recobra y se universaliza su ejercicio.

\section{d. Derecho a la integridad física y moral}

Es importante mencionar que no sólo la jurisprudencia interna ha enriquecido el listado de derechos, pues se cuenta también con lo dispuesto por el TEDH, el cual de acuerdo con su sentencia de 7 de julio de 1989 , caso Soering Vs. Reino Unido ${ }^{37}$ determina, que resulta ser un derecho protegible y tutelable, el no ser sujeto de algún trato inhumano o degradante, de tal suerte, que un Estado no podrá autorizar la extracción de una persona cuando existan indicios de que dicha persona puede ser sujeto de algún tratamiento de esta naturaleza, tal y como se hará referencia con mayor amplitud en seguida. Como se verá mas adelante este caso irradia sus efectos sobre otros derechos tales como las libertades de circulación y de residencia.

\section{e. Derecho a la libertad personal y al habeas corpus}

Otro de los derechos que se encuentra en el catálogo y que puede ser predicado de los extranjeros es el de la libertad personal y hábeas corpus, al cual la jurisprudencia del

\footnotetext{
37 Francia, Tribunal Europeo de Derechos Humanos (1989 julio), Sentencia del Tribunal Europeo de Derechos Humanos Soering Vs. Reino Unido. Estrasburgo. En este caso se deja sentado por parte del TEDH que la prohibición del artículo 3 tiene carácter absoluto y que este derecho no puede ser suspendido ni siquiera en el evento en el que en los Estados existan circunstancias excepcionales .
} 


\section{REVISTA VIRTUAL VIA INVENIENDI ET |UDICAND|}

"CAMINO DEL HALLAZGO Y DEL JUICIO"

http://viei.usta.edu.co/ E-MAIL: revistainveniendi@usantotomas.edu.co

TC en numerosos fallos ha dado alcance interpretativo, en el sentido, que supone que la inadmisión de este recurso solamente procederá en aquellos casos en los que se cumpla con los requisitos mínimos dispuestos por la Ley y en los que no haga falta presupuesto respecto de la situación concreta de la privación de la libertad, toda vez, que esto supone la violación al artículo 17.4 de la Constitución, de acuerdo con el cual se prevé que la Ley regulará un procedimiento para promover la inmediata puesta a disposición judicial de toda persona que haya sido detenida de manera ilegal. Dentro de ellos deben tenerse en cuenta las sentencias STC 256 de $2006^{38}$, STC 260 de $2006^{39}$, STC 201 de $2006^{40}$, STC 315 de $2005^{41}$, STC 342 de $2005 .{ }^{42}$

\section{f. Derecho de asociación, de reunión y de huelga}

La STC 115 de 1987 da algunas directrices para la interpretación del derecho de reunión que tienen los extranjeros, y sobre éste, se anota que la reunión privada es una potestad que tienen estos sujetos sin que medie autorización para ello. Así mismo se establece la regla para el caso de la reunión que se lleve a cabo en un lugar cerrado. No ocurre lo mismo sobre aquella que se realice en un lugar público, como quiera que en estos eventos será necesario que se dé notificación a la autoridad para que ésta pueda realizarse. La mencionada sentencia declara la inconstitucionalidad del artículo 7 de la Ley Orgánica 7 de 1987, según la cual, se hacían algunas imposiciones extraordinarias al ejercicio de este derecho, las cuales consistían en exigir permiso a las autoridades competentes en aquellas reuniones que se realizaran en un lugar cerrado y en las que eran llevadas a cabo en lugares donde existiera afluencia de tránsito

\footnotetext{
${ }^{38}$ España, Tribunal Constitucional (2007 diciembre) Sentencia Tribunal Constitucional 256, Madrid.

${ }^{39}$ España, Tribunal Constitucional (2007 diciembre) Sentencia Tribunal Constitucional 260, Madrid.

${ }^{40}$ España, Tribunal Constitucional (2006 mayo) Sentencia Tribunal Constitucional 201, Madrid.

${ }^{41}$ España, Tribunal Constitucional (2006 diciembre) Sentencia Tribunal Constitucional 315, Madrid.

${ }^{42}$ España, Tribunal Constitucional (2005 diciembre) Sentencia Tribunal Constitucional 342, Madrid, Para complementar el tema acudir a las sentencias STC 317 de 317 de 2005, STC 318 de 2005, STC 319 de 2005, STC 320 de 2005, STC 211 de 2006, STC 321 de 2005.
} 
REVISTA VIRTUAL VIA INVENIENDI ET IUDICANDI

"CAMINO DEL HALLAZGO Y DEL JUICIO"

http://viei.usta.edu.co/ E-MAIL: revistainveniendi@usantotomas.edu.co

público. ${ }^{43}$ No obstante ello se reproducen artículos que limitan este derecho en la posterior Ley 8 de 2000, tal y como se observará a continuación.

Dentro de los puntos básicos resueltos por el alto Tribunal en la antes citada STC 236 de $2007^{44}$ y que puede fijar parámetros para la interpretación de todos los derechos de los extranjeros, puede resaltarse el refuerzo que se hace a los límites impuestos al legislador a la luz de los preceptos constitucionales consagrados en el Título I, y los derivados de las obligaciones internacionales provenientes de los tratados en derechos humanos que han sido ratificados por el Estado. ${ }^{45}$ En el fallo se afirma también que los derechos que se otorgan a los extranjeros teniendo en cuenta que pertenecen a la esencia misma del ser humano o vinculados a su dignidad no son taxativos, sino enunciativos, lo que ratifica el dinamismo de los derechos humanos y su permanente creación. Si bien en principio todos los derechos pueden verse vinculados con la dignidad humana, debe analizarse cada derecho en concreto, a fin de determinar si entra dentro de esta categoría de derecho universal o no, de lo que se aduce que en efecto estos derechos se pueden flexibilizar y es el legislador el que determina en un preciso momento si algún derecho que no se encuentre dentro del catálogo podrá hacer parte del mismo en cabeza de los extranjeros. ${ }^{46}$

\footnotetext{
${ }^{43}$ El fundamento jurídico segundo dispuso que ...” Esta libertad de reunión sin autorización se constituye así en una facultad necesaria de autorización para que sea reconocible como pertinente al tipo descrito (sentencia del Tribunal Constitucional de 8 de abril de 1981); al imponerse la necesidad de autorización administrativa se está desnaturalizando el derecho de reunión, consagrado en la Constitución sin supeditarlo a la valoración discrecional y al acto habilitante y de poder implícito de la administración”

${ }^{44}$ España, Tribunal Constitucional (2007 noviembre) Sentencia Tribunal Constitucional 236, Madrid.

${ }^{45}$ Fundamento jurídico No. 1, dispone que “... en efecto el legislador al que remite el artículo 13.1 de la C.E. no goza de la igual libertad para regular la titularidad y el ejercicio de los distintos derechos del Título I, pues aquella depende del concreto derecho afectado. Como ha quedado bien dicho, una interpretación sistemática del repetido precepto constitucional impide sostener que los extranjeros gozarán en España sólo de los derechos y libertades que establezcan los tratados y el legislador, dejando en manos de este la potestad de decidir que derechos del título I les pueden corresponder y cuales no..."

${ }^{46}$ Arenas Hidalgo, N. (2008) La reciente jurisprudencia constitucional en materia de extranjería: comentarios a la Sentencia del Tribunal Constitucional relativa a la inconstitucionalidad de la Ley 8 de 2000, en Derecho migratorio y extranjería, 17, 33-58.
} 


\section{REVISTA VIRTUAL VIA INVENIENDI ET |UDICAND|}

"CAMINO DEL HALLAZGO Y DEL JUICIO"

http://viei.usta.edu.co/ E-MAIL: revistainveniendi@usantotomas.edu.co

Al analizar los cargos propuestos por el Parlamento de Navarra, el T.C. fundado en la argumentación antes anotada de que el legislador encuentra un límite infranqueable cuando a través de su actuación toca la dignidad humana, rescata los derechos a la reunión pacífica, el derecho de asociación, el derecho a la conformación o participación en los sindicatos y el derecho de huelga. La Constitución de 1978 en principio y atendiendo a su redacción original, prescribe una amplia aplicación de estas garantías a los individuos, sin establecer mayores consideraciones respecto de condiciones cualificantes como la residencia o la ciudadanía. No obstante, al observar el texto de la Ley 8 de 2000, tal y como se anotó en otro de los acápites de este trabajo, se establece una condición específica para el disfrute de estos derechos, la cual consiste en ostentar la residencia, o tener una autorización de estancia ${ }^{47}$, lo cual supone por supuesto encontrarse en condiciones de legalidad y en posesión de los documentos que acrediten un estatus ajustado a la normatividad española. A contrario sensu, quienes se encuentran en situación irregular se encontrarán por tanto impedidos del acceso a este derecho. Adicionalmente se impone en virtud de la Ley, la exigencia de una autorización para poder ejercitar el derecho en el evento de hallarse en cumplimiento de la legalidad.

La sentencia recobra la garantía en cabeza de los extranjeros y deja en claro que la norma legal contraría la constitución, toda vez que estos derechos son de titularidad universal y el legislador no puede extralimitarse y entrar a imponer requisitos cualificantes para su ejercicio.

Otro aspecto que puede considerarse como limitante a la actuación de la potestad legislativa es la finalidad o naturaleza del derecho, de modo que el legislador no podrá emitir normas que hagan que el derecho garantizado en la constitución se convierta en

\footnotetext{
${ }^{47}$ El artículo 7 de la Ley 8 de 2000 relativo a las libertades de reunión y de manifestación dispone que: "Los extranjeros tendrán el derecho de reunión, conforme a las leyes que lo regulan para los españoles y que podrán ejercer cuando obtengan autorización de estancia o residencia en España.»
} 


\section{REVISTA VIRTUAL VIA INVENIENDI ET |UDICAND|}

"CAMINO DEL HALLAZGO Y DEL JUICIO"

http://viei.usta.edu.co/ E-MAIL: revistainveniendi@usantotomas.edu.co

una garantía impracticable. De otro lado y al referirse a los tratados internacionales, en el fallo en mención se reafirma la primacía de la Constitución sobre los instrumentos internacionales, de suerte que solamente serán exigibles estas disposiciones en la medida en que también se encuentren consagradas en la Constitución y sirva como criterios interpretativos, lo que evidencia la ausencia de un valor autónomo respecto de lo que disponga el tratado internacional.

Al referirse al derecho de reunión el T.C. efectúa una conexión entre éste y la libertad de expresión, adicionalmente es suficiente para éste organismo que la misma Constitución de 1978 haya determinado la garantía de este derecho para "Todos" los individuos, lo que hace que sea expulsada la restricción contenida en el Ley 8 de 2000 y así, se haga extensible este derecho para los extranjeros que carecen de la documentación requerida por el Estado español. La limitación a este derecho creada por el legislador, es estimada por el T.C. como desproporcionada, y no justificable en una sociedad democrática.

En lo que se refiere a la STC 259 de diciembre de $2007^{48}$ (fallo en el que se examinan diversos artículos de la Ley 8 de 2000) muchos de los cargos de inconstitucionalidad habían sido tratados por el anterior fallo proferido en materia de extranjería, por lo que se considera por parte del T.C. en la parte resolutiva de la providencia, que frente a estos aspectos desaparece sobrevenidamente el objeto de la controversia jurídica. No obstante lo anterior en lo atinente al derecho a la huelga se realiza unas precisiones que vale la pena anotar. En el fundamento Jurídico 7 de la providencia se aclara que en atención a la redacción del artículo 8.1 del PIDCP los Estados quedan comprometidos a garantizar que a través de su legislación interna se haga practicable el derecho a la huelga, y por tanto se debe abstener de medidas que permitan su limitación. La relevancia de este pronunciamiento radica en que reivindica el valor de los instrumentos

\footnotetext{
${ }^{48}$ España, Tribunal Constitucional (2007 diciembre) Sentencia Tribunal Constitucional 259, Madrid. En esta sentencia se resuelve el recurso de inconstitucionalidad interpuesto por el letrado de la Junta de Andalucía, y la cual se dirige en contra de diversos artículos de la Ley 8 de 2000.
} 


\section{REVISTA VIRTUAL VIA INVENIENDI ET |UDICAND|}

"CAMINO DEL HALLAZGO Y DEL JUICIO"

http://viei.usta.edu.co/ E-MAIL: revistainveniendi@usantotomas.edu.co

internacionales dentro del ordenamiento jurídico español, toda vez que en el fallo anterior quedó mas bien determinado que los mismos no tenían un valor autónomo, sin embargo y pese a que no dice exactamente lo contrario, a partir de la aplicación de las normas internacionales se expulsan del ordenamiento algunas expresiones que resultar contradictorias con el espíritu de la constitución y con la naturaleza jurídica del derecho de huelga. ${ }^{49}$

A su turno las posteriores sentencias de 20 de diciembre de 2007, es decir la STC $262^{50} 263^{51}$ y $264^{52}$, el T.C declaran extinguidos los recursos por existir dos pronunciamientos anteriores que se ocupan de resolver las cuestiones planteadas por estas Comunidades Autónomas.

\section{g. Derecho a la libertad de circulación y residencia}

En lo atinente al derecho a la libertad de circulación y de residencia, la tendencia ya no se observa tan abierta y por el contrario, puede afirmarse que se está en frente de un tema en el que la jurisprudencia ha sido restrictiva. La STC 94 de $1993^{53}$, determina con base en el artículo 19 de la C.E. que si bien, es un ejercicio de la soberanía de los Estados imponer medidas que repercutan sobre la libre circulación de las personas, tales medidas deberán ser razonables y acordes con el artículo 13 del PIDCP. El fallo retoma precedentes en este aspecto y se limita a ratificar que el poder legislativo se encuentra en plenitud de sus competencias al regular los límites de los derechos de los

\footnotetext{
${ }^{49}$ Se expulsa del ordenamiento la expresión "cuando estén autorizados a trabajar” que se encontraba contemplada en el artículo 11.2 de la Ley orgánica 4 de 2008, reformada por la Ley 8 de 2000 y que condicionaba a la legalidad el ejercicio del derecho.

${ }^{50}$ Resuelve el recurso de inconstitucionalidad interpuesto por el letrado de la Junta de de las Comunidades CastillaLa Mancha contra diversos preceptos de la Ley 8 de 2000.

${ }^{51}$ Resuelve el recurso de inconstitucionalidad interpuesto por el letrado de la Comunidad Autónoma de Aragón en contra de algunos artículos de la Ley 8 de 2000.

${ }^{52}$ Resuelve el recurso de inconstitucionalidad interpuesto por el letrado de la Junta de Extremadura.

${ }^{53}$ España Tribunal Constitucional (1993 abril) Sentencia Tribunal Constitucional 94, Madrid, Fundamento Jurídico No. 3
} 


\section{REVISTA VIRTUAL VIA INVENIENDI ET |UDICAND|}

"CAMINO DEL HALLAZGO Y DEL JUICIO"

http://viei.usta.edu.co/ E-MAIL: revistainveniendi@usantotomas.edu.co

extranjeros, como lo es en este caso concreto, la exigencia de la legalidad para ejercitar el derecho. Se exhorta además que el diseñador de las políticas no puede perder de vista las exigencias impuestas por los instrumentos internacionales.

El planteamiento sobre este derecho obedece tal y como se ha referenciado, a la soberanía del Estado y a la inexistencia o por lo menos a la falta de claridad por parte de los instrumentos internacionales sobre un derecho a "inmigrar", recabando en que si bien existe el derecho a emigrar, éste se encuentra incompleto por el hecho de que no exista una libertad de asentarse libremente en otro territorio que no sea en el de la nacionalidad del individuo.

Cabe anotar que la Sentencia del Tribunal Supremo de 10 de junio de 2004, realiza una declaración importante en lo que tiene que ver con el derecho de residencia de los extranjeros. Determina, que algunas sentencias del Tribunal Constitucional ${ }^{54}$ han establecido que si bien de acuerdo con el artículo 19 de la Constitución se hace un reconocimiento solamente a los españoles para que puedan elegir libremente su residencia y para circular por el territorio nacional, dichos pronunciamientos han hecho extensivo este derecho para los extranjeros, en virtud de la norma que establece que los mismos, podrán gozar de los derechos y libertades que se encuentran consagrados en el Título I de la constitución. Lo anterior implica que los extranjeros son titulares de los derechos fundamentales a residir y a desplazarse de manera libre por el territorio nacional.

El Tribunal anota de nuevo que en efecto, el legislador ostenta la libertad para regular el tema de los extranjeros, pero que no puede olvidarse, ni dejar de aplicar las disposiciones de los tratados internacionales como por ejemplo el PIDCP y el protocolo

\footnotetext{
${ }^{54}$ Ver también STC 22 de mayo, STC 107 de 1984, STC 99 de 1985, STC 115 de 1987.
} 


\section{REVISTA VIRTUAL VIA INVENIENDI ET |UDICAND|}

"CAMINO DEL HALLAZGO Y DEL JUICIO"

http://viei.usta.edu.co/ E-MAIL: revistainveniendi@usantotomas.edu.co

4 del $\mathrm{CEDH}^{55}$, los cuales determinan los derechos de los extranjeros en condición jurídica de legalidad respecto a la libertad de circulación. Es importante anotar que el referido protocolo adicional fue firmado por el Estado español el 23 de febrero de 1978, pero que aún no lo ha ratificado. No obstante lo anterior en virtud de lo consagrado en el artículo 18 de la Convención de Viena sobre Derecho de los Tratados de 1969, tiene la obligación de abstenerse de aquellos actos en virtud de los cuales se frustren el objeto y fin de este instrumento. ${ }^{56}$

En este mismo sentido, la STC 94 de $1993^{57}$, reitera lo anterior, considerando que el extranjero podrá gozar de la libertad de circulación. Ello de realizar una interpretación extensiva del artículo 13 de la Constitución de 1978, sin perjuicio de que la Ley interna pueda regular las circunstancias en las que esto se hará o imponga los requisitos para que proceda, como por ejemplo las condiciones de legalidad de la residencia del extranjero. En este fallo se evidencia claramente la tensión que se presenta entre la garantía de los derechos humanos y el ejercicio de la soberanía por parte de los Estados, sin embargo este último principio hace inclinar la balanza hacia su lado y se limitan la libertad de circulación.

Como puede notarse la intervención del Tribunal Europeo de Derechos Humanos en el tema de extranjería ha resultado muy relevante, toda vez, que se fijan algunos parámetros de interpretación. Tal es el caso de la STEDH de 7 de julio de 1989, caso Soering Vs Reino Unido, en el cual se determinan algunos límites para los Estados partes en el CEDH, a la hora de aplicar una expulsión de un extranjero de un territorio y llevarlo a su lugar de origen. Se parte de la base de no poder infringirse tratos

\footnotetext{
${ }^{55}$ Protocolo Adicional suscrito en Estrasburgo el 16 de septiembre de 1963, según el cual se reconocen ciertos derechos, ya contenidos en el CEDH, como lo son la libertad de circulación y el derecho a escoger libremente el lugar de residencia haciéndolos extensivos a toda persona que se encuentre legalmente en el territorio de un Estado.

${ }^{56}$ Carillo Salcedo, J.A. (2003) El Convenio Europeo de Derechos Humanos. Madrid: Tecnos

${ }^{57}$ España Tribunal Constitucional (1993 abril) Sentencia Tribunal Constitucional 94, Madrid, Fundamento Jurídico No. 4
} 


\section{REVISTA VIRTUAL VIA INVENIENDI ET |UDICAND|}

"CAMINO DEL HALLAZGO Y DEL JUICIO"

http://viei.usta.edu.co/ E-MAIL: revistainveniendi@usantotomas.edu.co

inhumanos o degradantes a los condenados extranjeros, toda vez que en el evento en el que se presuma que se pone en riesgo su vida, o que con motivo de la expulsión será sometido a tratos inhumanos o degradantes no se podrá expulsar ésta persona, para evitar la ocurrencia de estos hechos que constituyan vulneración a los DDHH. Lo anterior en virtud de la aplicación del artículo $3^{\circ}$ del $\mathrm{CEDH}$, que dispone que no se podrá extraditar a una persona cuando haya posibilidades de que sea sometido a tortura o malos tratos en el Estado al que sea llevado. Si bien en este fallo es claro que se trata del derecho a la integridad personal y a la prohibición de ser sujeto de tratos inhumanos o degradantes, estos fallos irradian sus efectos en las libertades de circulación y de residencia. ${ }^{58}$

La STC 24 de 2000 trata este tema y fija los límites al derecho de residencia, estableciendo que las autoridades españolas deciden las condiciones de residencia de los extranjeros y establecen los supuestos y procedimientos de expulsión, los cuales tendrán que encontrarse fundados en una decisión contenida en la Ley, y en los casos de expulsión de los extranjeros, éstos tienen derecho a ser escuchados y al respeto del derecho a la tutela judicial efectiva.

Se da gran relevancia en esta providencia a los límites fijados por instrumentos internacionales como el PIDCP, en este caso concreto, para la procedencia de la expulsión de aquellas personas que residan de manera legal en el territorio español, estableciendo que en estos casos deberá darse primacía al principio de legalidad y al derecho de defensa. Cabe anotar, que esta disposición se refiere exclusivamente a los inmigrantes que se encuentran en posesión de la documentación y se excluyen a quienes por el contrario no los tienen, lo que llevaría a cuestionar, si en el caso de los inmigrantes que se encuentran en situación jurídica de irregularidad, éstos tendrán que

\footnotetext{
${ }^{58}$ En este mismo sentido, se pueden referenciar las sentencias STEDH de 30 de 1991, caso Varas y otros Vs. Suiza, 30 de octubre 1991, caso Vilvarajh Vs. Reino Unido, 15 de noviembre de 1996, caso Chahal Vs. Reino Unido, 11 de julio de 2000, caso Jabari Vs Turquía, 6 de marzo de 2001, caso Hilal Vs. Reino Unido.
} 


\section{REVISTA VIRTUAL VIA INVENIENDI ET |UDICAND|}

"CAMINO DEL HALLAZGO Y DEL JUICIO"

http://viei.usta.edu.co/ E-MAIL: revistainveniendi@usantotomas.edu.co

estar sujetos a una serie de arbitrariedades, o sometidos a conductas, que si bien atienden en principio a la consecuencia natural de una sanción, podrán desbordar su competencia y generar vulneraciones a los derechos de los individuos en esta situación.

\section{h. Derecho a la reagrupación familiar}

Frente a la reagrupación familiar, tal y como se observó anteriormente, éste derecho se encontraba garantizado de manera más amplia en la Ley 4 de 2000, y es restringido con la expedición de la Ley 8 de 2000. Esta postura restrictiva se mantiene pues de acuerdo con la STC 236 de 2007 antes enunciada, uno de los cargos que se formula por parte del Parlamento de Navarra, es precisamente la regulación que se presenta frente a este derecho y la disminución de los familiares reagrupables, así como los estrictos requisitos que se plantean para que este derecho sea ejercitable por parte de los extranjeros. Frente a este punto el T.C. considera infundado el cargo de inconstitucionalidad presentado en la demanda y en su lugar estima que toda vez que el derecho a la reagrupación familiar no se considera en la C.E como un derecho fundamental y que no es muy clara su vinculación con el derecho a la intimidad familiar, el legislador puede dentro de sus potestades regular las condiciones en las que se efectúe. ${ }^{59}$ Los argumentos del T.C. a primera vista se compadecen con lo previsto en las normas del artículo 8 del Convenio Europeo de Derechos Humanos, sin embargo reconoce que pese a que haya jurisprudencia del TEDH sobre el particular no se hace una declaración expresa de que este sea un derecho auténtico, esta afirmación desconoce el grueso de sentencias del TEDH en las que ha reconocido el derecho a la reagrupación familiar como un derecho derivado del artículo 8 del Convenio, es decir del derecho a la vida familiar. ${ }^{60}$

\footnotetext{
${ }^{59}$ España Tribunal Constitucional (2007 noviembre) Sentencia Tribunal Constitucional 236, Madrid, Fundamento Jurídico No. 11

${ }^{60}$ Ver los casos del Tribunal Europeo de Derechos Humanos Bouchelkia contra Francia, Beljoudi contra Francia, Dalia contra Francia, Nasri contra Francia, Abdulaziz, Cabales y Balkandali contra Reino Unido.
} 


\section{REVISTA VIRTUAL VIA INVENIENDI ET |UDICAND|}

"CAMINO DEL HALLAZGO Y DEL JUICIO"

http://viei.usta.edu.co/ E-MAIL: revistainveniendi@usantotomas.edu.co

Por su parte la sentencia del Tribunal de Justicia de las Comunidades Europeas de 19 de octubre de 2004, al hablar sobre el derecho de residencia índica una precisión importante sobre el derecho a la reagrupación familiar, al indicar que la residencia se debe hacer extensiva a toda aquella persona que se encuentre encargada de cuidar a un menor de edad. Ello constituye uno de los fundamentos de la reagrupación familiar y reviste importancia toda vez que da una protección especial a la familia como núcleo fundante de la sociedad.

Sobre este punto, la sentencia determinó que para que sea efectivo el derecho de un menor, es necesario que su progenitor o aquella persona que se encuentre a cargo de su subsistencia puedan radicarse en el mismo lugar en el que se encuentra este. Lo anterior siempre y cuando se demuestre que se cuenta con los recursos económicos suficientes para la supervivencia, tal y como sucede con los fallos del Tribunal Constitucional.

En su lugar el Tribunal Supremo examinando la situación en sentencia de 21 de mayo de 2001 ha considerado la importancia del derecho a la reagrupación familiar y en su lugar censura fuertemente la actual legislación de extranjería, en razón a que a su juicio establece un requisito desproporcionado para el reconocimiento de este derecho, el cual consiste en que para efectos de la reagrupación del cónyuge es necesario que éste demuestre que ha residido legalmente en el territorio nacional por un término que no podrá ser inferior a un año. Con tal requisito el T.S estima que se puede llegar a soslayar el derecho al matrimonio y en consecuencia el derecho a la familia. ${ }^{61}$

\footnotetext{
${ }^{61}$ Artículo 18. Procedimiento para la reagrupación familiar.

1. Los extranjeros que deseen ejercer este derecho deberán solicitar una autorización de residencia por reagrupación familiar a favor de los miembros de su familia que deseen reagrupar. Al mismo tiempo, deberán aportar la prueba de que disponen de un alojamiento adecuado y de los medios de subsistencia suficientes para atender las necesidades de su familia una vez reagrupada.
} 
REVISTA VIRTUAL VIA INVENIENDI ET IUDICANDI

"CAMINO DEL HALLAZGO Y DEL JUICIO"

http://viei.usta.edu.co/ E-MAIL: revistainveniendi@usantotomas.edu.co

\section{Conclusiones}

A lo largo del desarrollo del artículo se trató de dilucidar un poco la problemática de la extranjería tan solo desde una de sus perspectivas; el acceso a los derechos de las personas que representan esta condición respecto de los derechos ejercitados por los ciudadanos. A partir de allí se hizo evidente que la Constitución Española ha mantenido desde sus orígenes una tendencia clásica respecto a esta diferenciación y que la misma, se erige como uno de sus pilares fundamentales para el desarrollo de la democracia. El planteamiento constitucional ha sido cuidadoso en determinar que categoría de derechos deben ser otorgados a los extranjeros y claro a los inmigrantes, sin embargo, ha dado gran margen de regulación a la Ley, la cual a la luz de los tratados internacionales se ha tenido que acoplar para no soslayar el contenido de los instrumentos que han sido adoptados por el Estado.

Así las cosas es evidente que el catalogo de derechos de los extranjeros encuentra su estructura primordial a partir de la redacción de los artículos de la Carta Fundamental, teniendo como epicentro el derecho a la igualdad, que si bien, fue en principio predicado de los españoles, se hace extensivo a los extranjeros, gracias a la interpretación efectuada por parte del Tribunal Constitucional. En su lugar, la Ley de extranjería se encarga de construir y dar detalles finales al ejercicio de estos derechos, toda vez, que no resulta suficiente el listado genérico determinado por la Constitución, y la misma, remite a la potestad legislativa la responsabilidad de fijar los límites de las garantías y controlar los aspectos minuciosos en este tema.

Si bien es claro que tanto las leyes como los reglamentos establecen el radio de acción de los derechos de los extranjeros, debe rescatarse el papel de la jurisprudencia en este aspecto, en razón a que sobre la base de los precedentes han surgido subreglas a

2. Podrán ejercer el derecho a la reagrupación con sus familiares en España cuando hayan residido legalmente un año y tengan autorización para residir al menos otro año. 


\section{REVISTA VIRTUAL VIA INVENIENDI ET |UDICAND|}

"CAMINO DEL HALLAZGO Y DEL JUICIO"

http://viei.usta.edu.co/ E-MAIL: revistainveniendi@usantotomas.edu.co

las Leyes, que han dado un mayor alcance a los derechos, los cuales se han inclinado por adoptar una postura garantista frente a éstos, y que inspirados no solamente en la Carta Política, sino en los instrumentos internacionales han pretendido universalizar las garantías ofertadas por el Estado.

No obstante lo anterior, desafortunadamente los fallos no han tenido mayor eco en lo que respecta al diseño e implementación de las políticas públicas aplicables a la inmigración, por el contrario una de las principales críticas formuladas a la legislación expedida hasta la fecha, ha sido su diametral separación de los planteamientos formulados por los Tribunales encargados de marcar lineamientos sobre la aplicación de los derechos humanos, lo que resulta desalentador toda vez que se desnaturaliza la vocación de colaboración que debe predicarse de las ramas del poder público.

En este mismo sentido puede afirmarse que la legislación en materia de extranjería se ha concentrado en orientar su enfoque hacia la protección de las fronteras a través de los controles policiales y la imposición de fuertes sanciones a quienes infrinjan las normas, apartándose de las recomendaciones realizadas por la Oficina del Alto Comisionado de las Naciones Unidas para los Derechos Humanos, en el tema específico de los migrantes, e iniciando un camino acelerado hacia la regresividad y la ausencia de garantismo en la protección de los derechos de los migrantes. Lo anterior se hace evidente en el gran número de derechos que fueron limitados con ocasión a la reforma de la Ley 4 de 2000, por parte de la Ley 8 del mismo año, según la cual se endurecen los requisitos para el acceso de los derechos de los migrantes y desaparecen otros que encontraban anteriormente dentro de su listado de garantías y que posteriormente son reivindicados luego de siete años con los mas recientes fallos del Tribunal Constitucional.

\section{Bibliografía}




\section{REVISTA VIRTUAL VIA INVENIENDI ET |UDICAND|}

"CAMINO DEL HALLAZGO Y DEL JUICIO"

http://viei.usta.edu.co/ E-MAIL: revistainveniendi@usantotomas.edu.co

Aldecoa Lazarraga Francisco (2007), Migraciones y desarrollo, II Jornadas iberoamericanas de estudios internacionales, Madrid, Marcial Pons.

Arenas Hidalgo Nicolás (2008), La reciente jurisprudencia constitucional en materia de extranjería: cometarios a la Sentencia del Tribunal Constitucional relativa a la inconstitucionalidad de la Ley Orgánica 8 de 2000. Revista de derecho migratorio y extranjería, Valladolid, editorial Lex Nova.

Carrillo Salcedo Juan Antonio (2001) "La soberanía de los Estados y derechos humanos en derecho internacional contemporáneo", Madrid, Editorial Tecnos.

De Lucas Javier (1994) El desafío de las fronteras, derechos humanos y xenofobia frente a una sociedad plural, Madrid, Ediciones temas de hoy.

De Lucas Javier (2001) Las condiciones de un pacto social sobre la inmigración en Inmigración y derechos humanos, Zaragoza, Mira.

Estrada Carrillo Vicente (1993), Extranjería, comentarios y análisis prácticos, Madrid, editorial Trivium.

España, Juan Carlos I, Cortes Generales (1985, 1 de abril ) Ley 7 de 1 de abril de 1985, sobre derechos y libertades de los extranjeros en España, BOE Número 0158, de 3 de julio de 1985, Madrid.

España, Juan Carlos I, Cortes Generales (2000, 11 de enero) Ley 4 de 11 de enero de 2000 sobre derechos y libertades de los extranjeros en España y su integración social, BOE Número 10, de 12 de enero de 2000, Madrid. 


\section{REVISTA VIRTUAL VIA INVENIENDI ET |UDICAND|}

"CAMINO DEL HALLAZGO Y DEL JUICIO"

http://viei.usta.edu.co/ E-MAIL: revistainveniendi@usantotomas.edu.co

España, Juan Carlos I, Cortes Generales (2000, 22 de diciembre) Ley 8 de 2000 , Ley 8 de 22 de diciembre de 2000, de reforma de la Ley Orgánica 4 de 11 de enero de 2000, sobre derechos y libertades de los extranjeros en España y su integración social, BOE Número 307, de 23 de diciembre de 2000, Madrid.

España (2006), segunda reimpresión, Constitución Española de 1978, Madrid, Tecnos.

López Sala Ana María (2005), Inmigrantes y Estados: la respuesta política ante la cuestión migratoria", Barcelona, Anthropos.

Tribunal Constitucional Español, Sentencia 107 de 1984, sala segunda, Madrid, 23 de noviembre.

Tribunal Constitucional Español, Sentencia 99 de 1985, sala segunda, Madrid, 30 de septiembre.

Tribunal Constitucional Español, Sentencia 115 de 1987, sala primera, Madrid, 7 de julio.

Tribunal Constitucional Español, Sentencia 71 de 1988, sala segunda, Madrid, 24 de abril.

Tribunal Constitucional Español, Sentencia 188 de 1991, sala primera, Madrid, 3 de octubre

Tribunal Constitucional Español, Sentencia, Sentencia 242 de 1994, sala primera, Madrid, 27 de julio.

Tribunal Constitucional Español, Sentencia 95 de 2003, sala plena, Madrid, 22 de mayo. 


\section{REVISTA VIRTUAL VIA INVENIENDI ET |UDICAND|}

"CAMINO DEL HALLAZGO Y DEL JUICIO"

http://viei.usta.edu.co/ E-MAIL: revistainveniendi@usantotomas.edu.co

Tribunal Constitucional Español, Sentencia 342 de 2005, sala primera, 5 de diciembre.

Tribunal Constitucional Español, Sentencia 315 de 2005, sala primera, 12 de diciembre.

Tribunal Constitucional Español, Sentencia 260 de 2006, sala plena, Madrid 20 de diciembre.

Tribunal Constitucional Español, Sentencia 236 de 2007, sala plena, Madrid, 7 de noviembre.

Tribunal Constitucional Español, Sentencia 256 de 2007, sala segunda, Madrid, 17 de diciembre

Tribunal Europeo de Derechos Humanos, Sentencia Soering Vs. Reino Unido.Francia, Tribunal Europeo de Derechos Humanos 1989, Estrasburgo, julio.

Tribunal Europeo de Derechos Humanos, Cruz Varas y otros Vs. Suiza, 1991, Estrasburgo, 30 de octubre.

Tribunal Europeo de Derechos Humanos, Vilvarajh Vs. Reino Unido, 1996, Estrasburgo, 15 de noviembre.

Tribunal Europeo de Derechos Humanos, Chahal Vs. Reino Unido, 2000, Estrasburgo, 11 de julio.

Tribunal Europeo de Derechos Humanos Jabari Vs Turquía, 2001, Estrasburgo, 6 de marzo. 
REVISTA VIRTUAL VIA INVENIENDI ET IUDICANDI

"CAMINO DEL HALLAZGO Y DEL JUICIO"

http://viei.usta.edu.co/ E-MAIL: revistainveniendi@usantotomas.edu.co

Tribunal Europeo de Derechos Humanos, Cuscani Vs Reino Unido, 2004, Estrasburgo, 24 de septiembre.

Tribunal de Justicia de las Comunidades Europeas, 2004, Luxemburgo, 19 de octubre.

Tribunal Supremo 2004, Madrid, Sentencia de 10 de junio.

Tribunal Supremo, 2001 Madrid, Sentencia de 21 de mayo.

http://www.echr.coe.int/ECHR/EN/Header/Case-law/HUDOC/HUDOC+database

http:// www.corteidh.or.cr

http://www.westlaw.es

http://www.oim.int

http://www.ilo.org/public/spanish/revue/index.htm 